The new journal will cover the scientific study of animal behaviour and will be open to reports of original research on animal behaviour and to theoretical papers calculated to promote the experimental study of the subject. Work on endocrinology and nerve physiology will be given its due share of space, so long as it is clearly related to and designed to illuminate the behaviour of the animal. The editors are Prof. H. Hediger (Basel); Prof. P. Palmgren (Helsingfors); Dr. W. H. Thorpe (Cambridge); and Dr. N. Tinbergen (Leyden). Behaviour will appear at first at irregular intervals in issues of about 160 pages, the frequency depending on the amount of material offered for publication and on the availability of suitable paper, etc. The price of a volume of about 320 pages will be about 20 Dutch guilders. It is being published by E. J. Brill of Leyden.

\section{Cambridge Summer School in Metal Physics}

A Summer School in Metal Physies will be held during September 1-12 inclusive in the Cavendish Laboratory, Cambridge. The School will provide an introduction to the application of physical methods to the examination and utilization of metals, and is intended for those whose researches require a more fundamentally physical approach than is usual in ordinary metallurgical and engineering practice. The lectures and demonstrations will deal with $(a)$ application of X-ray methods in the examination of metals, (b) physical and mechanical properties of metals. Both parts will be taken by all attending the School, and for part $(a)$ an elementary knowledge of $\mathbf{X}$-ray diffraction methods and of crystal symmetry will be assumed; during the School it will be possible to provide only a very brief review of these aspects of the subject-matter. A detailed syllabus and form of application for admission can be obtained from G. F. Hickson, secretary of the Board of Extra-mural Studies, Stuart House, Cambridge, to whom the completed application form should be returned not later than June 7.

\section{University of Glasgow}

THE bicentenary of the institution of a lectureship in chemistry in the University of Glasgow falls during the present session. Dr. William Cullen was appointed in 1747 and held the lectureship for nine years, being succeeded by Dr. Joseph Black in 1756. To celebrate the bicentenary, four lectures will be given in the Department of Chemistry, on May 9, 16, 23 and 30, by Dr. Douglas Guthrie, on "William Cullen and His Times"; Prof. John Read, on "Joseph Black, the Tea her and the Man"; Dr. Alexander Fleck, on "Scottish Industrial Development of the Cullen/Black Period"; Prof. A. R. Todd, on "Glasgow Chemistry in the Twentieth Century".

\section{Society ,for Experimental Biology: Utrecht Meeting}

THE Society for Experimental Biology is holding a meeting at Utrecht during April 11-14; this is the first foreign meeting which the Society has held. An invitation to hold the meeting in Utrecht was given by the botanists and zoologists of the University of Utrecht, on the initiative of Prof. G. J. van Oordt, who had been a visitor at the Society's meeting last year at Newcastle. Papers will be presented by both British and Dutch workers in the field of experimental biology. A party of about seventy British scientific workers will be visiting Utrecht for the meeting.
Many topics will come under discussion, including some aspects of entomology and parasitology, histogenesis, electro-physiology, respiration of both animals and plants, permeability phenomena and plant hormones. On Sunday, April 13, there will be no formal sessions, but two expeditions, one to the reclaimed areas of the Zuider Zee, and the other to the bulb fields; . On this evening, all those attending the conference will dine together at Amsterdam.

\section{Servo-Mechanisms}

A RAPIDLy growing literature gives some indication of the extent to which war-time developments of automatic control systems or servo-mechanisms are finding application in industry. These applications range from relatively simple remote-position control systems to the overall control of complete industrial processes. A specialized theoretical technique has been evolved for the design of such systems and the analysis of their behaviour. A number of papers on the various aspects of this subject will be presented at a Convention on Automatic Regulators and Servomechanisms to be held at the Institution of Electrical Engineers during May 19-23.

\section{Announcements}

Dr. E. D. MerriLl, Arnold professor of botany at Harvard University, has been made an honorary staff member of the Botanic Gardens, Buitenzorg, Java. A diploma was handed to him by Dr. C. G. G.J. van Steenis, senior botanist of the Gardens, at a dinner for the editorial board of Chronica Botanica during the recent Boston meetings of the American Association.

THE Herbert Jackson Prize for 1946 of the London, Midland and Scottish Railway has been awarded to Mr. J. O. Cowburn, formerly engineering research assistant, Derby, for a paper entitled "The Development of a Successful Leakage-Testing Instrument for use on Vehicles fitted with the Automatic Vacuum Brake".

Mr. Wildiam Wrluiamson, joint author of the Ray Society volumes "The British Hydracarina", vols. 1-3 (1925-29), has presented to the library of the Royal Society of Edinburgh more than a thousand papers and a number of volumes dealing with the Hydracarina. Specimens have been lodged with the Royal Scottish Museum, Edinburgh, the Department of Zoology of the University of Edinburgh, and the British Museum (Natural History), London.

THe X-Ray Analysis Group of the Institute of Physics has recently established an X-Ray Tube Panel, under the chairmanship of Dr. A. Taylor. The Panel will review existing and projected $\mathrm{X}$-ray tubes and X-ray tube production in Great Britain. A questionnaire is being sent to all members of the X-Ray Analysis Group of the Institute and to certain others known to be interested in erystallographic $\mathrm{X}$-ray tubes. Communications should be sent to the honorary secretary of the Panel, Mr. J. N. Kellar, Crystallographic Laboratory, Cavendish Laboratory, Cambridge.

Erratum.-In "Role of Sulphydryl Groups in the Action of Acetylcholine and Inhibition of the Vagus Nerve" by Prof. Ch. S. Koschtojanz and T. M. Turpajew published in Nature of December 7, 1946, p. 837, paragraph 5, last line, for "cystein" read "cystine". 